\title{
REPRESENTAÇÕES SOCIAIS DE UM ESPAÇO FLORESTAL: O PARQUE NATURAL MUNICIPAL DA FREGUESIA (RIO DE JANEIRO/RJ) COMO ÁREA DE LAZER
}

\author{
Eduardo Silva de Freitas ${ }^{1}$
}

Resumo: Buscou-se identificar a representação social do Parque Natural Municipal da Freguesia, mais conhecido como Bosque da Freguesia, a partir do discurso de um dos seus mais importantes grupos usuários, os Amigos do Bosque. Utilizamos a metodologia proposta por Lefèvre et al., que pressupõe a análise do discurso do sujeito coletivo. Os resultados trouxeram à tona cinco ideias centrais, em torno das quais se consolida a representação social do Bosque da Freguesia. São elas: Patrimônio público; Refúgio; Relações humanas; Ambiente natural e Área de lazer. A última é a que mais se destaca e, de fato, estrutura sua representação. Tal interpretação encontra apoio nos discursos que as outras ideias centrais nos trazem, revelando uma concepção fortemente utilitarista do Bosque. Diante de tais resultados, entendemos que a educação ambiental tornase imprescindível, configurando-se em uma poderosa ferramenta de cidadania.

Palavras-chave: Meio ambiente. Representações sociais. Educação ambiental.

\section{SOCIAL REPRESENTATIONS OF A FOREST AREA: THE MUNICIPAL NATURAL PARK IN FREGUESIA (RIO DE JANEIRO/RJ) AS A LEISURE AREA}

Abstract: We sought to identify the social representation of the Municipal Natural Park in Freguesia, well known as Bosque da Freguesia (Wood of Freguesia), through the analysis of the discourse of one of the most important group of its users, the socalled Amigos do Bosque (Friends of the Wood). By means of the methodology proposed by Lefèvre et. al.,that presupposes the analysis of the collective subject discourse. The results brought five central ideas, which consolidate the social representation of the Wood of Freguesia, which are: public Patrimony; Refuge; Human Relations; Natural environment and leisure area. And that the idea that structures the social representation of the Wood of Freguesia is that of leisure area. The last one is the most interesting idea and, naturally represents better the wood. This interpretation finds support in the discourse that other central ideas bring, revealing a strongly utilitarian conception of the wood. With such results, it is possible to understand that the environmental education becomes indispensable, and have been a powerful tool of citizenship.

Keywords: Environment. Social representations. Environmental education.

\footnotetext{
${ }^{1}$ Mestre em Tecnologia Educacional nas Ciências da Saúde pela UFRJ. Docente da educação básica nos Municípios do Rio de Janeiro/RJ e de Duque de Caxias/RJ. efreitasbio@gmail.com
} 


\section{LAS REPRESENTACIONES SOCIALES DE UN ÁREA FORESTAL: PARQUE NATURAL MUNICIPAL EN FREGUESIA (RÍO DE JANEIRO/RJ) COMO ÁREA DE RECREACIÓN}

Resumen: Se intento identificar las representaciones sociales del Parque Natural Municipal, más conocido como Bosque de la Freguesia, desde el discurso de uno de sus más importantes grupos de usuarios, los Amigos del Bosque. Utilizamos la metodología propuesta por Lefèvre et al., que requiere el análisis del discurso del sujeto colectivo. Los resultados pusieron de manifiesto cinco ideas centrales que consolidan la representación social del Bosque de la Freguesia. Ellos son: la equidad pública; refugio; relaciones humanas; entorno natural y zona de recreo. Este último es el que se destaca, y, de hecho, estructura su representación. Tal interpretación encuentra apoyo en los discursos que otras ideas centrales nos traen, que revela una concepción fuertemente utilitaria del Bosque. Teniendo en cuenta estos resultados, creemos que la educación ambiental se convierte en indispensable, y esto presenta una herramienta de gran alcance para la ciudadanía.

Palabras clave: Medio Ambiente. Representaciones sociales. Educación ambiental.

\section{Introdução}

Este trabalho utiliza a abordagem das representações sociais (RS), originadas no trabalho pioneiro ${ }^{2}$ do pesquisador francês Serge Moscovici, com o intuito de contribuir para reflexões socioeducativas dentro da grande área Meio Ambiente.

Os programas de educação ambiental (EA) devem se apoiar nas representações produzidas pelos diversos grupos sociais, e seu trabalho é o de realizar intervenções sobre essas representações (TREVISOL, 2004). Em outras palavras, diversos estudos vêm sendo desenvolvidos, seguindo essa orientação e/ou tendência. Aqui, buscamos contribuir com a identificação das representações de mais um desses grupos sociais.

A investigação recaiu sobre usuários de um espaço florestal protegido, o Parque Natural Municipal da Freguesia, e foram as suas representações alvos de nosso interesse. Essa visão vem ao encontro do que pensam Silva, Gomes e Santos (2005), que afirmam a importância da teoria das RS como instrumento de gestão ambiental e de educação.

Situado no bairro da Freguesia, em Jacarepaguá, Zona Oeste do Município do Rio de Janeiro, o Parque Natural Municipal da Freguesia é mais conhecido como Bosque da Freguesia. Trata-se de um espaço criado por Lei Municipal, legitimado por Lei Federal como área de proteção integral. O espaço é categorizado como Parque Municipal, fato que o equipara aos Parques Nacionais, segundo a referida legislação (BRASIL, 2000). O parque está localizado dentro de uma área de proteção ambiental no Município do Rio de Janeiro - APA da Freguesia.

Podemos considerar o Bosque da Freguesia como parte remanescente da Mata Atlântica ${ }^{3}$, que é um complexo e exuberante conjunto de ecossistemas, abrigando uma

2 "La Psychanalyse, son image et son public", que veio a ser uma tese de doutoramento, foi publicada originalmente em 1961, dando origem à grande teoria, expressão defendida por alguns pesquisadores referindo-se à teoria das representações sociais (SÁ, 1998). 
parcela significativa da diversidade biológica do Brasil. Sua importância é reconhecida, nacional e internacionalmente, no âmbito científico, não somente pela sua rica biodiversidade e complexidade inquestionável, mas, também, pela originalidade resultante do endemismo inerente à Mata (FUNDAÇÃO SOS MATA ATLÂNTICA/INPE, 2002). Sua perda e destruição são incalculáveis e irreversíveis (DEAN, 2004).

Uma única copa de árvore pode abrigar mil espécies de insetos e a Mata Atlântica como um todo pode ter abrigado um milhão delas, das quais apenas pequena percentagem foi, ou será um dia, batizada pelos cientistas (...). Diversos locais da Mata Atlântica têm sido postulados como centros de endemismo de pássaros, mamíferos, répteis e insetos (DEAN, 2004, p. 33).

O Bosque, que se encontra imerso em um espaço urbano, é frequentemente discutido. Em uma dessas diversas discussões, no contexto de um bate-papo informal entre usuários e moradores próximos ao Parque, no ano de 2001, surgiu a seguinte fala de um dos cidadãos presentes: "Mas também... pra que esse monte de mato aí? Por que não acabam logo com isso? (...) Bota fogo logo! Isso não serve pra nada! Fica aí um monte de mato... Deserto... Aumenta a violência".

O Bosque da Freguesia, mencionado e caracterizado por aquele cidadão como uma espécie de entidade, responsável pela violência no local, trouxe à tona, algum tempo depois, o presente trabalho, cujo desenvolvimento e resultado apresento a seguir.

A partir da constatação de que o Bosque não parecia ser uma modalidade de espaço (urbano) importante para a qualidade de vida da região, argumentamos, após aqueles primeiros comentários, que ele: 1) seria o responsável por influenciar parcialmente o clima da região; 2) representaria um remanescente florestal de Mata Atlântica, ligado anteriormente à Floresta da Tijuca ${ }^{4}$, sendo a Mata Atlântica um bioma extremamente ameaçado, cuja imensa riqueza de fauna e flora vem sendo dizimada e degradada velozmente ao longo do tempo; 3) possuiria uma grande capacidade de reter água, como potencial das florestas em geral, abastecendo lençóis freáticos e rios; e 4) além de tudo isso, configura-se em um espaço público, favorecendo o lazer, de forma gratuita, e as relações humanas de modo geral.

Tínhamos a impressão de que bastaria uma boa argumentação científica para que aqueles cidadãos pudessem rever seus conceitos e perceber seus equívocos. No entanto, todos esses argumentos se mostraram inúteis para aqueles indivíduos que ali debatiam sobre a localidade, o que indicava a possibilidade de que seus discursos pudessem estar disseminados por entre os vários grupos que utilizavam o Bosque. Tal foi hipótese inicial, pensada por um então estudante de licenciatura do curso de Ciências Biológicas.

Nossas expectativas eram de que as informações transmitidas cotidianamente pelos diversos meios (TVs, materiais impressos, rádio, internet etc.) à sociedade sobre meio ambiente já tivessem consolidado certa consciência ambiental e o sentido

\footnotetext{
3 Na verdade, o Bosque da Freguesia é composto por uma vegetação secundária, mas segundo os botânicos Sá e Kurtz (1998), os remanescentes florestais secundários são mantidos no mesmo status das florestas primárias pela legislação brasileira, em função da crescente extinção dos remanescentes florestais primários.

${ }^{4}$ Preocupado com a falta d'água que afetava a cidade do Rio de Janeiro, o Imperador D. Pedro II mandou plantar a Floresta da Tijuca, em 1861, sendo este o primeiro exemplo, no Brasil, de reconstituição de cobertura vegetal com espécies nativas. Está localizada na região central da cidade, separando as Zonas Norte e Sul. Entre os paralelos $22^{\circ} 55^{\prime}$ e $23^{\circ} 01^{\prime}$ de latitude sul e os meridianos $43^{\circ} 12^{\prime}$ e $43^{\circ} 19^{\prime}$ de longitude oeste.
} 
preservacionista. Nesse sentido, a natureza por si, já seria algo que demandasse um valor intrínseco. Diante de tais fatos, acreditávamos que já existisse uma legitimação para a necessidade de proteção dos espaços naturais, estando tais ideias já razoavelmente assimiladas dentro da sociedade. Contudo, aquela conversa desmentiu essa expectativa. desafio.

Nas palavras de Costa Lima (1998), mudar tal quadro é, de fato, um grande

\begin{abstract}
Há, em primeiro lugar, que reconhecer-se que a consciência e o discurso ecológicos se expandiram mais rapidamente que os comportamentos e ações práticas. Portanto, o primeiro desafio consiste, justamente, em materializar idéias e teorias em práticas cotidianas ecologicamente orientadas (COSTA LIMA, 1998, p.150).
\end{abstract}

Tal entendimento sobre a necessidade de mudar tais pensamentos nos impeliu à reflexão, durante um bom tempo, até que resolvêssemos nos aprofundar, anos mais tarde, durante o mestrado, sobre tal situação. Na intenção de analisar a situação descrita anteriormente, buscamos as RS de um grupo usuário tradicional do espaço do Bosque. Dentre seus componentes, temos sujeitos que utilizam o Bosque de forma cotidiana, caracterizando o que Wagner (2000) chama de grupo reflexivo, isto é, reunião indivíduos que possuam a consciência de pertencerem a um grupo e que tenham critérios próprios (explícita ou implicitamente) de filiação. Isto permite-nos inferir que, nos resultados das representações, as opiniões fortuitas e sem alicerce na realidade do cotidiano são minimizadas.

Na busca pelas RS que envolvem o Bosque da Freguesia, nossa pretensão foi a de identificar e discutir as percepções, conceitos, valores, ideias e imagens que possuem os usuários do Bosque - como em geral, nas sociedades brasileiras, em espaços urbanos semelhantes ao Rio de Janeiro -, ressaltando que esses indivíduos estão expostos, indistintamente, a programas e projetos de EA diversos, propostos pela mídia, por governos, por ONGs etc. Ressalta-se que a pressuposta ideia ligada à modificação imediata naqueles discursos já estava afastada, por motivos de amadurecimento do pesquisador.

Em resumo, a pesquisa aqui relatada buscou captar a compreensão dos Amigos do Bosque, em relação ao Parque Natural Municipal da Freguesia, popularmente conhecido como Bosque da Freguesia, tendo como principal instrumento analítico a teoria das RS. Entendemos que tais resultados de pesquisa se mostram importantes e contribuem criticamente com as experiências de EA realizadas em espaços semelhantes ao Bosque da Freguesia.

\title{
2 Representações Sociais e Educação Ambiental
}

Pode-se afirmar que o conceito de RS é polissêmico e que mesmo Serge Moscovici, o pai da grande teoria, durante todo o tempo de desenvolvimento de seu pensamento, vem esquivando-se de uma definição fechada. Segundo Sá (2002, p.43), Moscovici tem "muitas "quase definições" de RS. Daí a necessidade de se destacar a definição sugerida por Jodelet (2001, p.22): "é uma forma de conhecimento, socialmente elaborada e partilhada, com um objetivo prático, e que contribui para a construção de uma realidade comum a um conjunto social". O consenso dessa definição encontra amparo em observações da literatura produzida nos últimos anos sobre RS, no 
Brasil. Outra tentativa de contornar o sentido das RS parece estar bem sintetizada na argumentação do próprio Moscovici (2001):

Representando-se uma coisa ou uma noção, não produzimos unicamente nossas próprias ideias e imagens: criamos e transmitimos um produto progressivamente elaborado em inúmeros lugares, segundo regras variadas. Dentro desses limites, o fenômeno pode ser denominado representação social (MOSCOVICI, 2001, p.63).

Para Jodelet (2001, p. 29), a identificação das RS pode "criar obstáculos ou servir de ponto de apoio para a assimilação do saber científico e técnico". As representações têm a função de ligar os sujeitos aos objetos, na medida em que servem para traduzir e dar significado aos mesmos.

Baseados nesses argumentos é que pensamos na teoria das RS como instrumento facilitador para conhecer o que pensam (ou poderiam pensar) os sujeitos, minimizando o problema da reificação acrítica de saberes ambientais, que desvaloriza os saberes comuns e marca uma orientação hierarquizada. A esse respeito Grün (1996, p.20) adverte-nos quanto à possibilidade de opressão às diversas culturas, sendo a EA exclusivamente reificada "um discurso altamente normativo de uma cultura branca e 'limpinha' que quer se impor a outras práticas culturais".

A EA teria diversas funções: criticidade e emancipação dos sujeitos, mudanças no comportamento e atitudes, encaminhamento para um pensar coletivo, à interdependência mútua etc. (JACOBI; TRISTÃO; FRANCO, 2009). Tudo isto vinculado ao diálogo de saberes, voltado à tentativa de minimizar aspectos da degradação ambiental em curso.

Diz Ruscheinsky (2001):

Muitos programas de educação ambiental possuem alcance mais limitado do que o projetado por órgãos governamentais com profissionais intencionais do ponto de vista técnico, porém que desdenham os condicionantes sociais, as representações e a dimensão participativa (RUSCHEINSKY, 2001, p. 29-30).

Pensamos que identificar e compreender o senso comum, que embasa comportamentos e atitudes dos seres humanos a respeito de meio ambiente favorece o encaminhamento de novos aportes educativos e qualificará reflexões sobre temas ambientais tanto para os educadores ambientais quanto para os educandos. Entretanto, um dos principais problemas vinculados a esta situação é encontrar, com precisão, as ancoragens dos discursos, o que nem sempre é fácil e que, no contexto deste trabalho, não nos foi possível apresentar.

Segundo Reigota (2002, p. 20): “A compreensão das diferentes representações deve ser a base da busca de negociação e solução dos problemas ambientais. Não se trata de saber quantitativamente mais, mas qualitativamente melhor [...]”.

\section{Metodologia}

A proposição teórica requerida pela teoria das RS é a de que sempre alguém (sujeito) representa alguma coisa (objeto). Dessa forma, de acordo com Sá (1998), devemos especificar bem o sujeito (a população ou o conjunto social) e o objeto, considerando-os simultaneamente. 
Diante disso, buscamos na pesquisa qualitativa o instrumento para acessar as representações de um determinado grupo, centrados na ideia de que a técnica de análise do discurso do sujeito coletivo (DSC), seguindo os passos propostos por Lefèvre, Lefèvre e Teixeira (2000), e de Lefèvre e Lefèvre (2003), é relevante e nos permite acesso direto e indireto às $\mathrm{RS}$, viabilizando o resgate de aspectos significativos dessas representações presentes nas sociedades.

\subsection{Sujeitos}

Os sujeitos envolvidos nesta pesquisa foram escolhidos por já estarem organizados há algum tempo e bem estabelecidos dentro do referido espaço, considerando o tempo de existência do Parque. Distribuem-se uniformemente entre as três faixas etárias consideradas por esta pesquisa. Todos têm mais de quarenta anos e $85 \%$ dos entrevistados possuem, no mínimo, o ensino fundamental completo. Possivelmente, sejam os mais fiéis usuários do local, assentando uma prática social no local (atividades desportivas). Caracterizam o grupo reflexivo, defendido por Wagner (2000), para trabalharmos as representações que se formam em seus discursos.

\subsection{O objeto}

O Bosque da Freguesia (Figura 1) por muito tempo foi um local praticamente abandonado, de mata fechada e densa, com apenas algumas trilhas feitas por moradores ribeirinhos e/ou de loteamentos residenciais próximos. É um Parque Natural, do Município do Rio de Janeiro, com vegetação remanescente da Mata Atlântica, antes ligada à Floresta da Tijuca. Possui cerca de 31 hectares em uma APA. Situado no Bairro da Freguesia, em Jacarepaguá, Zona Oeste do Município do Rio de Janeiro. Trata-se de um parque urbano, cercado por muitas residências e algumas grandes indústrias: Frangos Rica, Guaravita e Ambev.

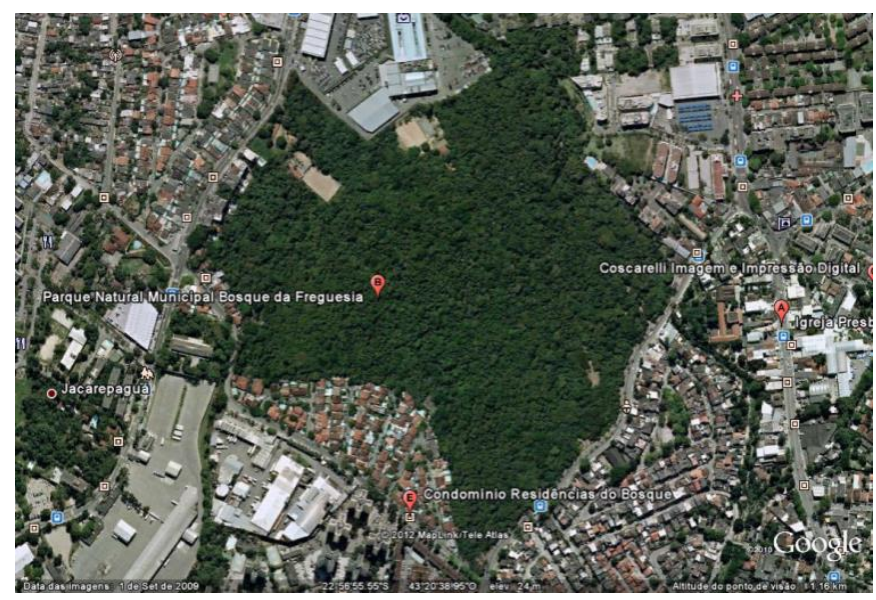

Figura 01 - O Bosque da Freguesia

Fonte: Google Earth 


\subsection{Entrevistas}

A realização das entrevistas ocorreu durante os eventos do grupo, que se juntava todas terças e quintas para o futebol de veteranos. Optamos pela proposta de organização e tabulação de dados qualitativos, obtidos mediante respostas verbais, gravadas e transcritas em editor de texto. Tais dados de pesquisa foram obtidos através de entrevistas semiestruturadas, em número de 40, entre abril e dezembro de 2004, todas realizadas sem a obrigatoriedade da identificação nominal dos entrevistados, sendo os mesmos tratados nas transcrições literais pela expressão $A B$ (Amigo do Bosque), seguido de uma numeração crescente (iniciada pelo número 1). Também foram coletadas informações sobre os entrevistados e suas opiniões, momentos antes e após as entrevistas, que buscaram caracterizar melhor a representação do Bosque da Freguesia, transcritas em um diário de campo de pesquisa.

Basicamente, as entrevistas foram organizadas segundo o seguinte roteiro: 1) Caracterização geral do Bosque; 2) Pontos positivos e negativos do Bosque; e 3) Reflexões e possibilidades quanto ao uso do Bosque.

\section{O Discurso do Sujeito Coletivo - DSC}

O DSC pressupõe, a priori, quatro figuras metodológicas, a saber: ancoragem, ideia central, expressões-chave e o DSC. A cada figura corresponde uma etapa da metodologia.

- Ancoragem: essa figura nos remete à noção de que existem pensamentos preexistentes, e que estes servem de substrato para classificarmos e denominarmos coisas. A ancoragem é um dos processos formadores das RS, mas é o mais difícil de ser constatado, porque depende muito do foco de interesse do pesquisador e nem sempre é de fácil apropriação pelo mesmo. As representações já disponíveis podem também servir de acolhimento a novas representações (SÁ, 1993).

- Ideia Central e expressões-chave: duas figuras metodológicas que se complementam diretamente. As ideias centrais são formuladas com base nas afirmações dos entrevistados que venham a permitir o entendimento do essencial dos conteúdos explicitados. Lefèvre, Lefèvre e Teixeira (2000, p.18) consideram que sejam "uma espécie de 'prova discursivo-empírica' da 'verdade' das ideias centrais e das ancoragens e vice-versa".

- Discurso do sujeito coletivo (DSC): o DSC é montado com expressões-chave (matéria-prima). Essa figura visa "reconstruir, com pedaços de discursos individuais, como em um quebra-cabeça, tantos discursos-síntese quantos se julgue necessário para expressar uma dada 'figura', ou seja, um dado pensar ou representação social sobre um fenômeno". É a principal figura metodológica (LEFÈVRE; LEFÈVRE; TEIXEIRA, 2000). Pequenos trechos dos DSCs produzidos estão disponíveis no Quadro 01:

\section{Pequenos trechos dos DSCS DSC PATRIMÔNIO PÚBLICO}

“(...) é um espaço maravilhoso da comunidade de Jacarepaguá, imprescindível (...). Temos que brigar por isso porque a tendência será crescer o número de pessoas que virão ao Bosque. Ele deve ser preservado para as pessoas novas (...). Isso aqui é nosso! Não se deve mexer nisso aqui! É um ambiente público, entendeu? Um espaço que é direito de todos, (...), para a gente usufruir da melhor maneira. (...). 
Você tem tudo aqui, e sem pagar nada. Mas, se isso aqui é área pública, a prefeitura poderia botar um enfermeiro, um médico... (...). Há anos atrás queriam desmoronar isso aqui tudo, desmatar, fazer prédio, fazer tudo... Mas pó! Destruir um patrimônio desse aqui? (...) Somos batalhadores para o tombamento do Bosque."

\section{DSC REFÚGIO}

"O Bosque é uma área que a gente pode se sentir bem. É um lugar seguro. (...) por causa da segurança, dos momentos de paz, de tranquilidade, de mais intimidade com Deus. É uma área que eu posso trazer as crianças, passear com meu filho, com a minha esposa, sem perigo. Tem espaços aí fora que eu não posso fazer nada disso. (...). Sei lá, para mim, isso aqui é o meu refúgio, né?

(...). É uma areazinha como se diz, relaxante. (...). 'Desestressar' aqui dentro é uma boa. Às vezes você está estressado, sai de casa, senta aqui de manhã, fica olhando, olhando, horas e horas. Às vezes nem anda cara! Você fica ali, sentadinho, olhando o Bosque, meditando, os passarinhos se movimentando, o miquinho correndo para um lado, para o outro, às vezes pega um livro...

\section{DSC RELAÇÕES HUMANAS}

“(...). Isso aqui é tão importante que é o mesmo que fosse um prato de comida para mim. É muito bom aqui, principalmente para os aposentados da terceira idade, que estavam em casa sem ter o que fazer. (...) O Bosque é um centro em que as pessoas se encontram, se reúnem, conversam e tudo, onde brincam juntas e reveem os amigos. É, os amigos... Eu venho de longe só para ver os amigos, bater papo com eles, distrair um pouco. (...) É isso aí, está me entendendo? É integração da galera toda. É o contato. São as pessoas de diversas idades, entendeu?

Imagino que qualquer dono de empresa gostaria de ter um clube igual a esse: um local de conviver bem.

\section{DSC AMBIENTE NATURAL}

"O Bosque da Freguesia, por causa do verde, é o pulmão daqui do pessoal, da área de Jacarepaguá. (...) também ajuda muito na convivência do ser humano, na adaptação com as árvores aqui, uma área toda arborizada, além de um ar purinho aqui, o oxigênio que temos, a oxigenação. É um prazer ter uma imensidão dessa de verde, a presença de quase uma mini floresta incrustada no meio da Freguesia. (...) Tudo isso contribui para se ter um ar puro. (...).

O Bosque, essa área ambiental, é um pedacinho de vegetação nativa aqui da região, faz parte do nosso ecossistema. (...). Aqui você tem o verde, tem os pássaros, tem saguis, tem tudo para desfrutar. (...). É um habitat natural que você não vai poder carregar daqui e colocar ali em uma praça pública, ou seja, não vai fazer igual aqui, ficar tudo verde, bonito.

(...)Isso aqui é natureza, a natureza em si.

\section{DSC ÁREA DE LAZER}

Nós temos poucos lugares de lazer e diversão aqui em Jacarepaguá. (...) Atualmente, é o melhor lugar da Freguesia para momentos de lazer. Uma área muito boa, perto de tudo: shopping, ônibus na porta. Ele trouxe esporte e lazer aqui para a Freguesia.

(...). Passamos a ter um local para caminhadas, exercícios diários, quer dizer... Isso aqui a partir das seis horas da manhã é uma festa diária! Um espaço para se praticar algum esporte, se preparar fisicamente, fazer ginástica, jogar futebol, fazer exercícios em geral, onde as pessoas vêm para caminhar, correr, zelar pela sua saúde. O Bosque é sinônimo de lazer e de saúde por tudo isso e também tem outros tipos de atividades, por exemplo, Ioga.

(...). Até que se pagasse, isso aqui seria melhor do que um clube. (...). Aqui é uma excelente área de lazer onde diminuímos e descarregamos o estresse do dia a dia. (...). Tem a ginástica pela manhã. É uma área muito boa para você ter lazer com as crianças, para você poder jogar um futebol, tua esposa poder fazer uma ginástica, né? Um meio para o pessoal que não tem onde... que não tem como gastar em diversão, vir brincar. Isso para mim é o Bosque da Freguesia! Afinal, a gente precisa de área de lazer e aqui o lazer completo.

O Bosque é uma praça de diversão, com entretenimento, alegria... Ah! Eu acho que é uma área de vida. O Bosque é tudo isso. É aqui que eu me divirto (...).

(...) o Bosque é uma área de lazer para nossa comunidade, que utilizamos diariamente, de segunda a segunda. Inclusive, fizemos uma equipe e botamos um nome: “Amigos do Bosque”. O grupo é muito bom. Todos da melhor qualidade.

(...). Antigamente, isso aqui era horrível e atualmente está como um Maracanã, um estádio, entendeu? (...) os espaços são adequados para o esporte, para a Educação Física, mas se pudesse, eu criaria uma área um pouquinho maior de lazer - trilhas de caminhadas, parte cultural, parte ecológica - com mais um campo society [futebol], mais uma quadra [poliesportiva], mais equipamentos de exercícios 
[musculação e ginástica]. Ampliaria também as atividades esportivas, como a ginástica feita para as pessoas da terceira idade. Enfim, seria um espaço onde poderíamos ter diversas atividades, sempre com um lazer gratuito.

Quadro 1 - Discursos

\section{Resultados e discussões}

De acordo com a Lei 9.985, cap. III, art 11, §1 (BRASIL, 2000) os Parques são de posse e domínio públicos. Dentro de tais características, o Bosque da Freguesia é usado pelos mais diversos grupos como ponto de encontro para práticas diversas (futebol, ginástica, caminhadas, corridas, piqueniques, grupos de orientação, massagens, relaxamentos, atendimento psicológico, Tai Chi Chuan, Ioga etc).

O diário de campo revelou uma preocupação com a questão da segurança ${ }^{5}$. Além disso, nos primeiros contatos informais com os Amigos do Bosque, surgiram alguns indícios de suas representações. Ouvimos, naqueles momentos, ideias a respeito de lazer, natureza, verde, diversão, refúgio etc., que foram ratificadas posteriormente pelos DSC construídos. Identificamos a ausência de algumas expressões importantes do ponto de vista ambientalista, tanto nas falas informais iniciais, como nos DSC posteriormente construídos: meio ambiente, sustentabilidade e educação ambiental. Esperávamos que esses termos estivessem explícitos nas manifestações dos sujeitos, não só porque os julgamos importantes, mas porque imaginávamos já estarem consagrados no cotidiano da população.

Pudemos identificar 5 ideias centrais nos depoimentos coletados nas entrevistas, com suas respectivas expressões-chave, e construir os respectivos DSCs. Eis os 5 DSCs: (1) Patrimônio público; (2) Ambiente natural; (3) Refúgio; (4) Relações humanas; e (5) Área de lazer.

O DSC Patrimônio Público revelou o Bosque como uma área que necessita manutenção contínua do poder público, no intuito de se proteger um espaço que é gratuito, da comunidade, de todos. Este DSC enfatizou o espaço como algo nosso, com sentido de preservação, de propriedade coletiva e social. Valorizou a ideia de preservação, no entanto, encontrava-se muito afastado de uma orientação ecológica de pensar a natureza do local em si, antes, vinculava-se à proteção de um espaço com potencial de lazer para a população.

Para o discurso retratado no DSC Ambiente natural, o Bosque seria um ecossistema (elementos bióticos: fauna e flora; e elementos abióticos: ar puro) especial, um local privilegiado cada dia mais escasso nas grandes cidades, que tem um ar mais limpo, sem poluição e com boa qualidade de vida. Contrapõe-se ao que se julga artificial, que seria o externo.

Como Refúgio, o Bosque seria um abrigo do caos urbano, apresentando alguns problemas da modernidade: violência, poluição e estresse. Como local das Relações Humanas remeteu a um espaço onde as pessoas formavam grupos sociais, faziam novas amizades, reviam antigos amigos, valorizavam o companheirismo e a diversidade humana.

\footnotetext{
${ }^{5}$ Nos horários matinais, o fluxo de indivíduos aumentava no Bosque da Freguesia, o que permitiria uma sensação maior de segurança, fato que não se repete em horários vespertinos, quando a quantidade de frequentadores caia significativamente, elevando a probabilidade de assaltos, abusos sexuais e intimidações, principalmente em locais mais afastados das trilhas principais (FREITAS, 2006).
} 
Como Área de Lazer, o Bosque seria um espaço destinado principalmente ao esporte e ao lazer, que favoreceria um entretenimento amplo e promoveria uma melhoria na saúde e na qualidade de vida dos indivíduos. Entre os cinco DSCs, a ideia do Bosque como Área de Lazer pode ser destacada pela exuberância nas manifestações dos sujeitos. Isso é facilmente observado quando notamos, em todos os outros DSCs, fortes referências à questão do lazer, cuja compreensão permite-nos inferir a estruturação da RS do grupo investigado fortemente atrelada a esse DSC.

Destacamos esse aspecto, mas ressaltamos que os outros DSCs também foram bem caracterizados em torno das suas respectivas ideias centrais, sugerindo que os discursos se complementam com uma proximidade bastante elevada. De acordo com a análise das participações individuais, o DSC Área de lazer foi construído por $85 \%$ dos entrevistados. A associação do Bosque a um local de Refúgio, por $70 \%$ dos sujeitos. As ideias que aproximavam o Bosque de Ambiente natural, local das Relações humanas e Patrimônio Público tiveram um índice próximo disso, com $67,5 \%$ de adesão cada uma delas.

O DSC Refúgio se aproxima do DSC Ambiente natural quando nos traz a imagem de um paraíso como reserva do bem. Apesar do DSC Refúgio também apresentar uma visão relativamente utilitarista, ela não está tão bem caracterizada quanto o DSC Ambiente natural, antes, revela mais proximidade com a interpretação cristã, baseada em sentimento de cuidado, de cultivo, de guarda e respeito àquele ambiente. Sob essa ótica, ambientes semelhantes ao Bosque da Freguesia fazem falta às sociedades pela possibilidade de atendimento de suas necessidades psicológicas e crenças diversas.

Há a indicação de uma consciência que retrata a importância de se ter uma área verde em áreas urbanas, sendo esta a principal característica do DSC Ambiente Natural. Marca-se, aqui, uma contraposição entre o espaço florestal em questão e seu ambiente exterior, lembrando a nostalgia associada, em princípio, ao povo inglês em meados do séc. XVIII quando o capitalismo modificou as relações sociais e produziu muita poluição (THOMAS, 1988).

O DSC Refúgio também se aproxima do DSC Relações Humanas, pois tratam da mesma visão, isto é, de sentir-se bem dentro do espaço do Bosque. Entretanto, diferenciam-se quanto aos modos de uso desse espaço. O DSC Refúgio valoriza também um contraponto ao urbano, fato que também é característico do DSC Área de lazer. Já o DSC Relações humanas valoriza a interação social.

$\mathrm{Na}$ opinião dos $\mathrm{AB}$, haveria uma bela e agradável minifloresta, identificada como o pulmão do bairro, que oferece oxigênio, sombra e frescor aos seres vivos. Tratase de uma natureza boa e bela, à disposição dos seres humanos e que se contrapõe ao ambiente urbano, uma coisa edificada pelo homem, sendo - a natureza - passível de preservação para nossos descendentes no futuro. Para eles, o importante é poder desfrutar de tudo isso, considerando o entendimento de que tudo isso é natural, virgem, e diferente do que se encontra fora do Bosque. Pesa sobre isso a impressão de que os $\mathrm{AB}$ não admitem, de forma explícita, reflexiva e/ou consciente, que esse espaço tenha sofrido uma intervenção muito significativa sobre sua área.

O fato de o Parque ter sido constituído a partir de um cenário natural (leia-se, especialmente, verde, animais e ar puro), talvez obscureça a ideia de que se trata de um espaço modificado significativamente pelo homem e que, ao longo do tempo, vem sendo sistematicamente agredido, incluindo a demanda para o lazer e a implementação 
de trilhas diversas. Além disso, a urbanização do bairro cresce a cada dia, pressionando sobremaneira os limites do Bosque.

Os sujeitos envolvidos na representação do Bosque como ambiente natural não avaliam que, as intervenções, cada vez mais frequentes, feitas pelos seres humanos prejudicam o dito (pensado) estado natural daquela localidade. Quanto essa ideia central, chamamos atenção para a extrema valorização da natureza. Há, sim, uma relação circunstancial de uso e apropriação dos recursos (por exemplo, possibilidade de um ar mais puro) e até de contemplação, o que não justificaria um comprometimento ecológico social para com o ambiente.

Permeando o discurso dos $\mathrm{AB}$, o discurso de afastamento do humano do que convencionamos, em ambientes especializados, chamar de natureza, é fato. Não há uma ideia de pertencimento, o que sinaliza um pragmatismo, indicando que a sociedade deva ser servida pela natureza. Já aos seres vivos não humanos essa relação é indissociável e indispensável, a ponto de colocar-se em jogo a sobrevivência deles: "Tem os animais que aqui dentro dependem disso aqui pra sobreviver entendeu?” (AB 21). Nesse caso, os animais são natureza. E nós, não?

\section{Considerações finais}

Após dois anos de intenso trabalho, pudemos compreender melhor a associação feita pelos cidadãos que motivaram as primeiras reflexões desta pesquisa, já devidamente relatadas em nossa introdução. Suas primeiras impressões, sustentadas nas expressões manifestadas por um deles: monte de mato, não serve pra nada, deserto e aumenta a violência, não formavam um discurso vazio, sem importância. Os resultados mostraram, por um lado, que associar o termo pejorativo monte de mato ao Bosque, pode ser entendido como uma compreensão de quem não usa o Bosque da Freguesia, associado a frágeis ou inexistentes informações sobre Mata Atlântica, preservação, problemas socioambientais etc. Aqueles que usam o espaço do Bosque, falam com a experiência de dentro e identificam utilidade, defendendo o espaço. A RS produzida pelo grupo pesquisado pode e deve servir como substrato em intervenções educativas no Bosque da Freguesia.

O processo educativo pode interferir em diversas verdades ligadas aos DSC, tendo como principal objetivo discutir aspectos da representação produzida. Sabe-se que as RS são muito estáveis, mas que não são cristalizadas. Para Moscovici (2003, p.41), após a criação das representações, "elas adquirem vida própria, circulam, se encontram, se atraem e se repelem e dão oportunidade ao nascimento de novas representações, enquanto velhas representações morrem".

É durante esses encontros e desencontros, na transição entre as velhas representações que morrem e as novas que nascem que, talvez, se encontre o ponto central para a EA. Como consequência desses entendimentos, e com base na teoria das RS, é que argumentamos a favor de auxiliarmos educacionalmente as transições entre a atual representação do Bosque pelos Amigos do Bosque e outras, mais qualificadas nos temas ambientais, fomentando reflexões e revisões de valores e atitudes.

Com relação a esse cenário aqui descrito, em apropriação à reflexão de Ruscheinsky (2003), concordamos que os resultados deste trabalho não se prestam a resolver de forma abrupta problemas ambientais e emergenciais, antes, contribuem, a partir de uma pesquisa de base empírica, com a reflexão multidisciplinar de questões socioambientais. 
O Bosque da Freguesia, afinal, pode ser considerado um espaço educativo, e, como tal, a dimensão de cidadania deveria estar presente. Isso parece associar-se à limitada consciência a respeito das características da Mata Atlântica do Bosque e as consequentes necessidades de preservação desse ecossistema. Se a consciência desse aspecto é limitada nesse grupo, também o é quanto à inclusão do ser humano enquanto parte da natureza.

O conjunto de limitações põe em cena a carência de programas continuados de EA informal, fato que ficou bastante claro, quando, em nossas entrevistas, ao discutirmos o terceiro tema proposto em nosso roteiro, nos deparamos com a valorização exacerbada do Bosque enquanto área de lazer.

A princípio, esse não seria um grande problema. Entretanto, o fato agravante concernente à questão socioambiental consiste em que, após uma breve caracterização de seus múltiplos usos, oferecíamos uma proposta imaginária: e se a Prefeitura oferecesse outro espaço para suas atividades desportivas organizadas, com boa infraestrutura, na forma de um clube, por exemplo, urbanizado e próximo do Bosque, dentro das imediações do bairro? Daqueles que defenderam veementemente o uso do Bosque como espaço de lazer, uma parcela bastante significativa passaria a usufruir desse novo espaço e deixaria o Bosque a mercê da especulação imobiliária em troca de patrocínio e/adoção desse novo clube.

É diante disso que nos preocupamos com a prevalência das manifestações que tratam o Bosque da Freguesia como área de lazer, pois entendemos que essa postura pode indicar um relativismo muito grande frente aos problemas ambientais atuais, o que demandaria um grande obstáculo para o seu enfrentamento.

Apontamos, baseados nos DSCs construídos, as seguintes propostas educativas: 1 - Debater os aspectos da valorização da dimensão 'entretenimento' no uso do espaço físico, considerando toda riqueza socioambiental que a unidade de conservação oferece (DSC Área de lazer); 2 - Discutir a necessidade reconhecimento do Bosque não apenas como um imóvel, cujo maior valor é o de ser público e objeto de exploração e uso, mas como um complexo ecológico biodiverso, importante para todas as espécies vivas (DSC Patrimônio público); 3 - Discutir noções e pertencimento do homem ao meio em que vive e interage, buscando superar a dicotomia sociedade-natureza (DSC Relações humanas e DSC Ambiente natural); 4 - Discutir o nosso cotidiano a partir de questões do tipo: afinal, por que a cada dia que passa estamos menos satisfeitos com nosso ambiente industrial-urbano, e, ainda assim, não somos capazes de modificar nossos comportamentos? Por que quase sempre atuamos apenas como agentes passivos diante de condições de vida opressoras, sem insistir em mudanças? (DSC Refúgio).

Certamente, a EA se faz necessária como instrumento de melhoria da qualidade de vida dos cidadãos, sendo, inclusive, dever do Estado e direito dos indivíduos. Portanto, é também instrumento de cidadania. Como todo processo educativo, a EA também deve ser caracterizada por uma política de continuidade, com resultados esperados para longo prazo, sobretudo sem tirar de foco a possibilidade de resultados alcançados, também, no curto e médio prazos, pois algumas reflexões feitas a partir da aproximação dos atores sociais com a EA podem proporcionar releituras de alguns valores e comportamentos sociais do cotidiano dos indivíduos e grupos. 


\section{Referências}

BRASIL. Lei $n^{\circ}$ 9.985, de 18 de julho de 2000. Regulamenta o art. 225, § $1^{\circ}$, incisos I, II, III e VII da Constituição Federal, institui o Sistema Nacional de Unidades de Conservação da Natureza e dá outras providências. Disponível em: 〈https://www.planalto.gov.br〉. Acesso em: 22 mai 2005.

COSTA LIMA, G.F. da. Consciência ecológica: emergência, obstáculos e desafios. Revista Eletrônica Política e Trabalho, João Pessoa, n. 14, p.139-154, Set. 1998. Disponível em: <http://www.oocities.org/collegepark/library/8429/14-costalima.html>. Acesso em: 22 out. 2014.

DEAN, W. A ferro e fogo: a história e a devastação da mata atlântica. $5^{\text {a }}$ reimp. São Paulo: Cia das Letras, 2004.

FREITAS, E.S. de. O discurso do sujeito coletivo e a representação social do Parque Natural Municipal da Freguesia: o que os "Amigos do Bosque" nos contam? 2006. 105 p. Dissertação (Mestrado em Tecnologia Educacional nas Ciências da Saúde) - Universidade Federal do Rio de Janeiro. Rio de Janeiro, 2006.

FUNDAÇÃO SOS MATA ATLÂNTICA/INPE. Atlas dos remanescentes florestais da Mata Atlântica e ecossistemas associados no período de 1995-2000. São Paulo. Relatório final, 2002. Disponível em: <http://www.rma.org.br/biblioteca.htm>. Acesso em: 26 mai 2005.

GRÜN, M. Ética e educação ambiental: a conexão necessária. Campinas: Papirus, 1996. (Coleção Magistério: formação e trabalho pedagógico).

JACOBI, P.R.; TRISTAO, M.; FRANCO, M.I.G.C. A função social da educação ambiental nas práticas colaborativas: participação e engajamento. Cad. CEDES, Campinas, v. 29, n. 77, p. 6379, Abr. 2009. Disponível em: <http://www.scielo.br/scielo.php?script=sci_arttext\&pid=S010132622009000100005>. Acesso em: 08 Fev. 2014.

JODELET, D. Representações sociais: um domínio em expansão. In: (Org.). As representações sociais. Rio de Janeiro: EdUERJ, 2001. p.17-44.

LEFÈVRE, F.; LEFÈVRE, A.M.C.; TEIXEIRA, J.J.V. (Orgs.). O discurso do sujeito coletivo: uma nova abordagem metodológica em pesquisa qualitativa. Caxias do Sul: EDUCS, 2000.

LEFÈVRE, F.; LEFÈVRE, A.M.C.; O Discurso do Sujeito Coletivo. Um novo enfoque em pesquisa qualitativa (Desdobramentos). Caxias do Sul: EDUCS, 2003.

MOSCOVICI, S. Das representações coletivas às representações sociais: elementos para uma história In: JODELET, D. (Org.). As representações sociais. Rio de Janeiro: EdUERJ, 2001. p.45-66.

MOSCOVICI, S. Representações sociais: investigações em psicologia social. Petrópolis: Vozes, 2003. (Coleção Psicologia Social)).

REIGOTA, M. Meio ambiente e representação social. 5 ed. São Paulo: Cortez, 2002 (Questões da nossa época, Vol. 41).

RUSCHEINSKY, A. Meio ambiente e percepção do real: os rumos da educação ambiental nas 
veias das ciências sociais. Rev. eletrônica Mestr. Educ. Ambient. Rio Grande, v.7, p.26-44, Out./Nov./Dez. 2001.

RUSCHEINSKY, A. Sociologia das representações sociais e a educação ambiental.

Contrapontos: Revista de Educação da Universidade do Vale do Itajaí, Itajaí, v.3, n.1, p.81-95, Jan./Abr. 2003.

SÁ, C.P. de. Representações sociais: o conceito e o estado atual da teoria. In: SPINK, M.J. (Org.). O conhecimento no cotidiano: as representações sociais na perspectiva da psicologia social. São Paulo: Brasiliense, 1993.

SÁ, C.P. de. A construção do objeto de pesquisa em representações sociais. Rio de Janeiro: EdUERJ, 1998.

SÁ, C.P. de. Núcleo central das representações sociais. Petrópolis: Vozes, 2002.

SÁ, C.F.C. de; KURTZ, B.C. Laudo técnico sobre a vegetação do Bosque da Freguesia. 1998. [Trabalho não publicado].

SILVA, L.M.A.; GOMES, E.T.A.; SANTOS, M.F. de S. Diferentes olhares sobre a natureza: representação social como instrumento para educação ambiental. Estudos de Psicologia. Natal, v.10, n.1, p.41-51, Jan./Abr. 2005.

THOMAS, K. O homem e o mundo natural: mudanças de atitude em relação às plantas e aos animais, 1500-1800. São Paulo: Cia das Letras, 1988.

TREVISOL J.V. Os professores e a educação ambiental: um estudo de representações sociais em docentes das Séries Iniciais do Ensino Fundamental. In: ENCONTRO DO ANPPAS, 2, 2004, São Paulo. Papers... São Paulo: ANPPAS; GT10, 2004. p.27-56.

WAGNER, W. Sociogênese e características das representações sociais. In MOREIRA, A.S.P.; OLIVEIRA, D.C. (Orgs.). Estudos interdisciplinares de representação social. $2^{\mathrm{a}}$ ed. Goiânia: AB, 2000. p.3-25. 